\title{
Factors influencing the sediment delivery ratio of the Three Gorges Reservoir
}

\author{
Dayu Wang*, Chunhong Hu, Chunming Fang, Jianzhao Guan, and Lei Zhang \\ Department of Sediment Research, China Institute of Water Resources and Hydopower Research, \\ Beijing, P.R. China
}

\begin{abstract}
In recent years, the sediment delivery ratio (SDR) of the Three Gorges reservoir (TGR) has noticeably decreased as a result of the increase in water levels at the dam site and the decrease in inflow of fine particles, thereby resulting in increased reservoir siltation. Therefore, it is vital to research the factors that influence the SDR of the TGR. Factors that could have impact on the SDR were studied using TGR monitoring data. The study indicated that the water level at the dam site and inflow and outflow rates could have contributed to the change in the SDR. A sensitivity analysis of the influencing factors was then carried out using a mathematical model to simulate numerous sediment movement scenarios in the TGR. By changing the input conditions of the model, sufficient results were obtained to enable a sensitivity analysis of each factor. The results showed the flood retention time (FRT) - the ratio of reservoir capacity to average outflow discharge-was the principal factor influencing the SDR. The other factors (inflow sediment concentration, inflow sediment coefficient, inflow sediment gradations, and the shape coefficient of the inflow flood shape coefficient), also had an influence on the SDR. However, under different levels of FRT, their degrees of influence on the SDR were not the same..
\end{abstract}

\section{Introduction}

The Three Gorges Project (TGP) is the world's largest hydropower project. It is located in the upstream of Yangtze River, China. The Three Gorges Reservoir (TGR) is a river-type reservoir. The operation of the TGP includes storing clear water in the dry season and discharging muddy flow in the flood season. To increase the sediment delivery ratio (SDR), the water level of the TGR is reduced in the flood season. Filling of the reservoir commenced in 2003, initially, the water level was kept at around $135 \mathrm{~m}$ in the flood season, and $139 \mathrm{~m}$ in the dry season. Subsequently, the water levels were gradually increased. Since October 2010, the water level had reached around $175 \mathrm{~m}$ in the dry

\footnotetext{
* Corresponding author: dayu.wang@hotmail.com
} 
season. However, in the flood season, there had been some fluctuations, with water level usually in the $145 \mathrm{~m}$ to $155 \mathrm{~m}$ range. When the water level at dam site was $175 \mathrm{~m}$, the backwaters area could reach $660 \mathrm{~km}$ in the upstream of the Three Gorges Dam.

In recent years, as a result of the implementation of cascade reservoirs upstream of the TGR, the inflow sediment has changed coarser. Around $80 \%$ of the inflow sediment of TGR was finer than $0.06 \mathrm{~mm}$, which has barely changed these years. However, the inflow sediment particle which was finer than $0.004 \mathrm{~mm}$ had decreased from $30 \%-40 \%$ to $20 \%-25 \%$ since 2010. What is more, the upstream cascade reservoirs and climate change have also resulted in the decrease of the inflow in September and October. In response to this situation, operational adjustments have been proposed. From 2010, the impounding time of the TGR has been advanced. In addition, in order to allow full utilisation of the TGR, the flood control level has been allowed to fluctuate within a certain range in the flood season. However, these measures could lead to siltation in the reservoir. Therefore, it is necessary to study the factors influencing the SDR of the TGR.

In previous research on the SDR of different reservoirs or rivers, the principal influencing factors on the SDR differed, including water level, sediment concentration and discharge. Formulae relating SDR and flood retention time (FRT) have been established using theoretical and empirical approaches [1-4]. These formulae use large amounts of observation data and focus on one or two of the main factors influencing SDR. Because the TGR operations have only been implemented from 2003, the observation data are limited. Huang has proposed a SDR formula for the TGR based on the FRT using regression of observation data, but without verification [5]. In general, research on the factors influencing the SDR of the TGR is limited [6]

\section{Data and Methods}

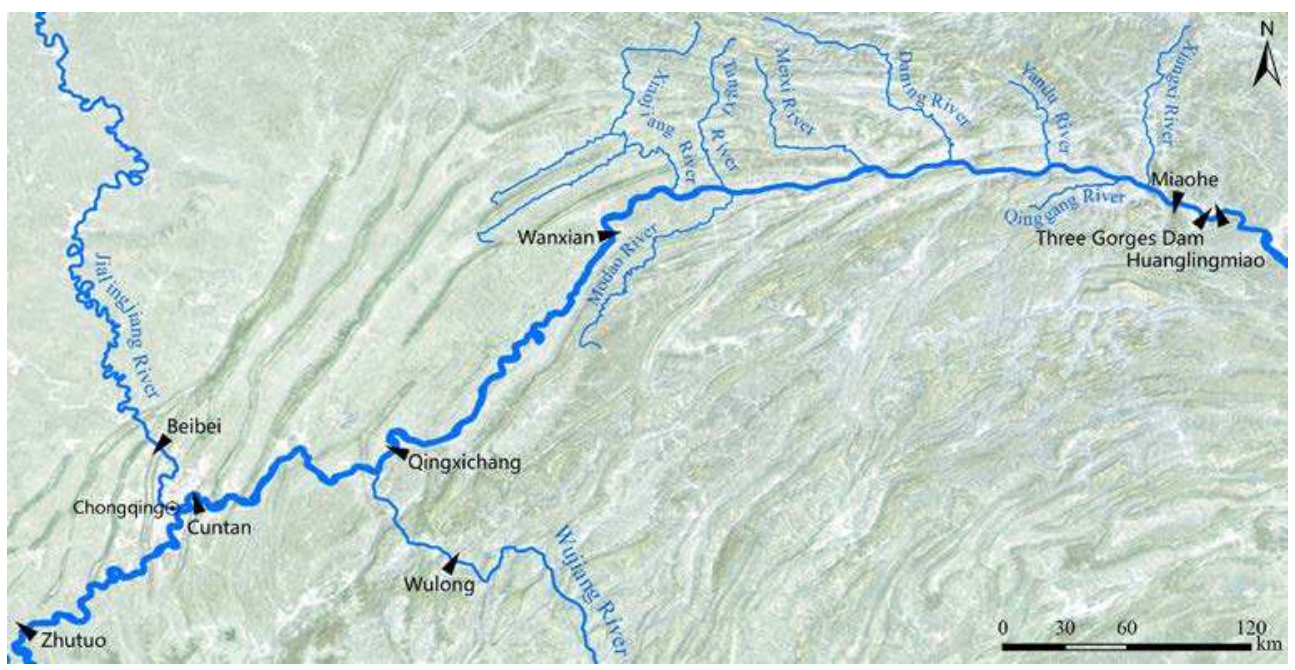

Fig. 1. Scaled map of the study area

This research was based on observation data and numerical simulation data of the TGR. Observation data was obtained from hydrometric stations in the TGR area of the Yangtze River (Fig.1). The inflow discharge and inflow sediment data of the TGR came from the Zhutuo hydrometric station, located at the Yangtze River, and from the Beibei and Wulong hydrometric stations, located on diversion channels of the Yangtze River. The outflow discharge and outflow sediment data for the TGR were obtained from the Huanglingmiao hydrometric station, which is located downstream of the TGR. The water levels at the dam 
site were collected from the Miaohe hydrometric station, located in front of the dam. All the observation data cover the period from June 2003 to December 2014. Only data for the flood season were used in this study because the inflow of sediment in the flood season accounted for $90.3 \%$ of the total mean annual inflow, and because the outflow of sediment in the flood season accounted for $96.0 \%$ of the mean annual outflow.

Numerical simulation data was obtained from a mathematical model (1D Flow-Sediment Model of TGR) that could simulate sediment transportation in the TGR under different water levels at the dam site, and different inflow rates and sediment concentrations. Results from the model have been validated in earlier studies on flow and sedimentation issues in the TGR [7]. The outflow rate and outflow sediment processes have all been well verified. Therefore, these numerical simulation results can be used to analyse the SDR of the TGR.

SDR in this study refers to the SDR based on the peak sediment transport in the TGR. This sediment peak can be observed on both the inflow and outflow suspended sediment concentration curves for the TGR, and can be regarded as a suspended sediment peak event. The statistical period of the SDR was taken from the arrival of the sediment peak in the reservoir to its departure. However, because floods usually take around one day to arrive at the dam of the TGR, the average inflow rate $\left(Q_{\text {in }}\right)$ was obtained from the day the sediment peak entered the reservoir to the day before the sediment peak exited the reservoir.. Likewise, the average outflow rate $\left(Q_{\text {out }}\right)$ was obtained from the day after the sediment peak entered the reservoir to the day the sediment peak exited. The inflow sediment peak usually takes 3 days or more to arrive at the dam. The average inflow sediment concentration $\left(S_{\text {in }}\right)$ was obtained during the inflow sediment peak period. The average outflow sediment concentration $\left(\mathrm{S}_{\text {out }}\right.$ ) was obtained during the outflow sediment peak period. In addition, the water level at the dam site (denoted by $\mathrm{Z}$ ) was the average water level during the whole transportation of the sediment peak in the reservoir.

The SDR statistics based on the observation data were used for the analysis of the relationships between the SDR and other hydrological factors, such as the water level at the dam site, flow rates, and sediment concentration. However, only a limited amount of data was available to determine the SDR. Therefore, a mathematical model was employed to simulate many cases of sediment movement in the reservoir. In the numerical simulation, the inflow water-sediment condition, and the water level at the dam site could be set as a combination, which resulted in a wide range of cases that could replicate almost all realworld possibilities. Four assumptions were made in the numerical simulation: (1) the inflow flood peak and inflow sediment peak were simultaneous at the entrance of the reservoir, (2) there were no other floods and sediment peak flows into the reservoir, (3) the water level at the dam site was constant during the whole process, and (4) the peak time of the inflow flood and the sediment peak were both 5 days. These were the ideal conditions for an inflow sediment peak. Without interference from other inflow sediment peaks and inflow floods, the inflow and outflow processes associated with the sediment peak and flood can be easily determined.

\section{Results and Discussion}

\subsection{Factors influencing SDR based on hydrological data}

A total of 32 sediment peaks were traced moving through the reservoir by observation data during the flood season. As a result, 32 SDRs and their influencing factors, such as water levels at the dam site, flow rates, and concentration of suspended sediment were obtained.

The relationship between the dam water levels and the SDR is shown in Fig. 2(a). In the 32 inflow sediment peak events, the highest SDR occurred when the water lever at the dam 
was around $135 \mathrm{~m}$, which was relatively low. It can be seen that as the water level at the dam site increased, the maximum value of the SDR decreased, in general. This indicates that the water level at the dam site had an obvious influence on the SDR. However, the water level was not the only factor affecting the SDR because the same water level was associated with different SDRs. However, the variation in the SDR decreased as the water level increased.
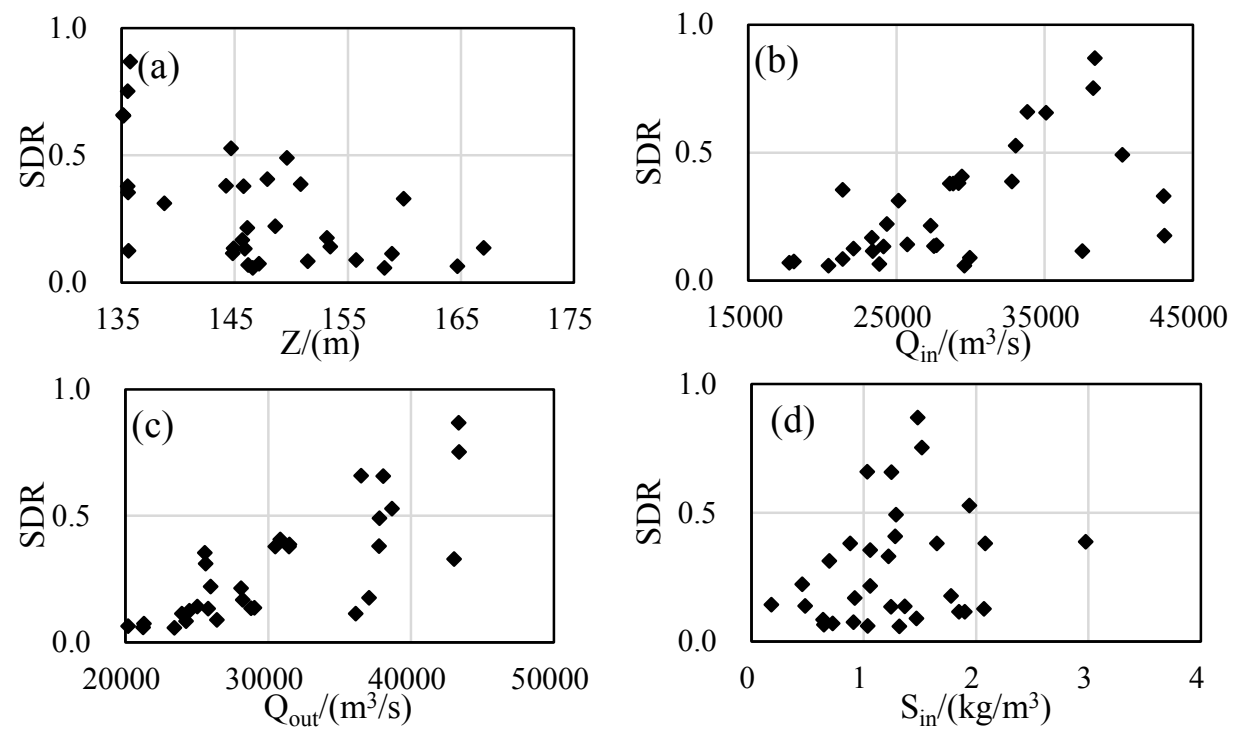

Fig. 2 The relationship between the SDR and its influencing factors

The inflow (Fig. 2(b)) and outflow (Fig. 2(c)) rates also had an influence on the SDR. Because the flow moves faster than the sediment in the reservoir, the flood that flows into the reservoir after the sediment peak could also assist the sediment transport. The outflow could also affect the sediment movement by changing the hydrodynamic conditions at the reservoir outlet. This suggests that the SDR could have a positive correlation with both inflow and outflow rates. However, the correlation of the SDR with the outflow rate was found to be greater than with the inflow rate. The inflow sediment concentration and the SDR did not show an obvious correlation (Fig. 2(d)).

The FRT, where FRT=V/Q out, was introduced to show how the FRT in the reservoir was related to both the water level at the dam site and the outflow rate. The volume of water in the TGR is denoted by V. In addition, the inflow sediment coefficient $\left(\mathrm{S}_{\text {in }} / \mathrm{Q}_{\text {in }}\right)$ was introduced to represent the inflow sediment concentration of unit inflow. A high sediment concentration of unit inflow would cause sediment concentration to exceed the sediment transport capacity, which would result in sedimentation in the reservoir. The relationship between the SDR and the FRT, and between the SDR and $\mathrm{S}_{\text {in }} / \mathrm{Q}_{\text {in }}$ are shown in Fig. 3.
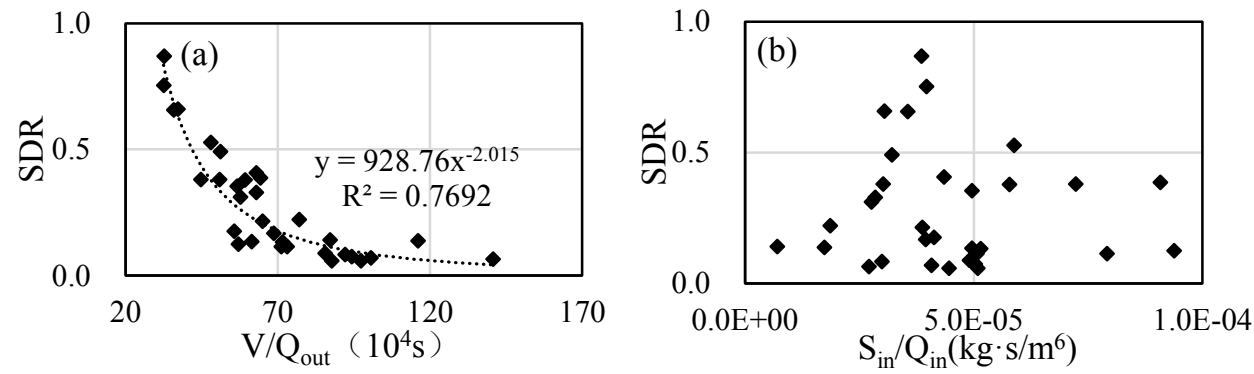

Fig. 3 The relationship between the SDR and the FRT 
It can be seen that the FRT and SDR have a relatively high correlation. As the FRT increases, the SDR decreases dramatically (Fig. 3(a)). However, no correlation could be seen between $S_{\text {in }} / Q_{\text {in }}$ and the SDR (Fig. 3(b)).

\subsection{Sensitivity analysis of factors influencing SDR}

A numerical model was employed to simulate the sediment transporting process in the reservoir for a sensitivity analysis of inflow rates and water levels at the dam site. Five different water levels were used (from $135 \mathrm{~m}$ to $155 \mathrm{~m}$ at $5 \mathrm{~m}$ increments). For each water level, the inflow flood rate was changed together with the inflow sediment peak. A total of 14 inflow floods rates were used, with peak rates $\left(Q_{\max }\right)$ from $25000 \mathrm{~m}^{3} / \mathrm{s}$ to $60000 \mathrm{~m}^{3} / \mathrm{s}$ at $5000 \mathrm{~m}^{3} / \mathrm{s}$ increments. The corresponding average inflow flood rates $\left(\mathrm{Q}_{5}\right)$ were 19800 $45600 \mathrm{~m}^{3} / \mathrm{s}$.

Fig. 4 indicates that SDR has a positive correlation with inflow rates and a negative correlation with water levels at the dam site. A higher water level resulted in a lower SDR, while a larger inflow resulted in a higher SDR. When the inflow rate increased, the SDR increased faster under low water levels than under high water levels. Because the water level at the dam site was stable during sediment movement in the reservoir, the relationship between outflow rates and the SDR would be the same as between inflow rates and the SDR.

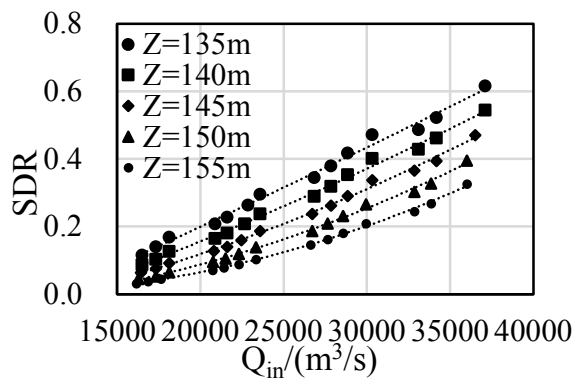

Fig. 4 The relationship between the SDR and inflow discharge for different dam water levels

From Fig. 5 it can be seen that as the flood retention time increased, the SDR decreased, but the rate of decreasing slowed down.

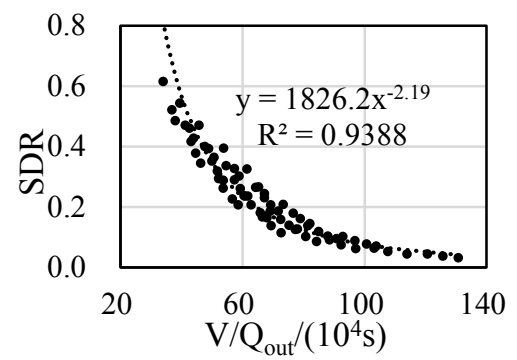

Fig. 5 The relationship between the SDR and the FRT
Table. 1 Different combinations of dam water levels and inflow flood rates

\begin{tabular}{ccccc}
\hline $\begin{array}{c}\text { Condition } \\
\text { No. }\end{array}$ & $\begin{array}{c}\mathrm{Z} / \\
(\mathrm{m})\end{array}$ & $\begin{array}{c}\text { Qb\&a/ } \\
\left(\mathrm{m}^{3} / \mathrm{s}\right)\end{array}$ & $\begin{array}{c}\mathrm{Q}_{5} / \\
\left(\mathrm{m}^{3} / \mathrm{s}\right)\end{array}$ & $\begin{array}{c}\mathrm{Q}_{\max } / \\
\left(\mathrm{m}^{3} / \mathrm{s}\right)\end{array}$ \\
\hline 1 & 135 & 30000 & 45600 & 60000 \\
2 & 145 & 30000 & 40000 & 50000 \\
3 & 145 & 25000 & 35000 & 45000 \\
4 & 145 & 20000 & 27400 & 35000 \\
5 & 145 & 15000 & 25000 & 35000 \\
6 & 150 & 15000 & 25000 & 35000 \\
7 & 155 & 15000 & 22400 & 30000 \\
\hline
\end{tabular}

Since both the water level at the dam site and the inflow rate had an obvious influence on the SDR, seven combinations of water levels and inflow rates were selected to represent different levels of FRT (Table 1). In these combinations, Qb\&a was the inflow rate before and after a flood, and $\mathrm{Q}_{\max }$ was the peak flood flow.

From Condition 1 to Condition 7, their FRTs were 34, 49, 57, 73, 89, 103, and $125 \times$ $104 \mathrm{~s}$, respectively. From the numerical simulation results (Fig. 6), it can be seen that although the inflow sediment concentration changed over a wide range, the principal influencing factor on the SDR was the FRT. For different values of FRT, the SDR decreased as the inflow sediment concentration increased. The SDR decreased faster for small FRTs than for large FRTs. 


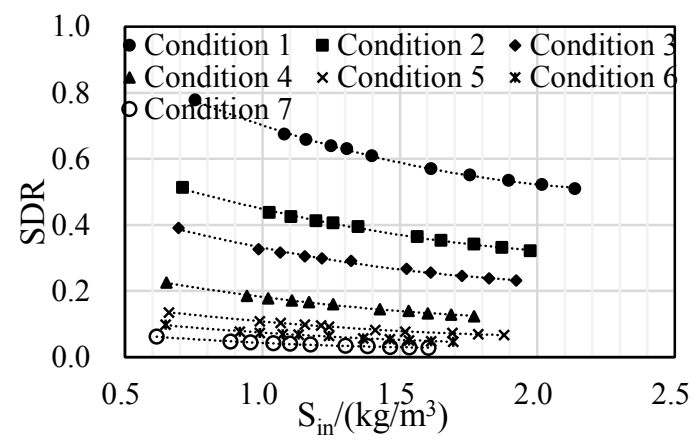

Fig. 6 The relationship between the SDR and inflow sediment concentration

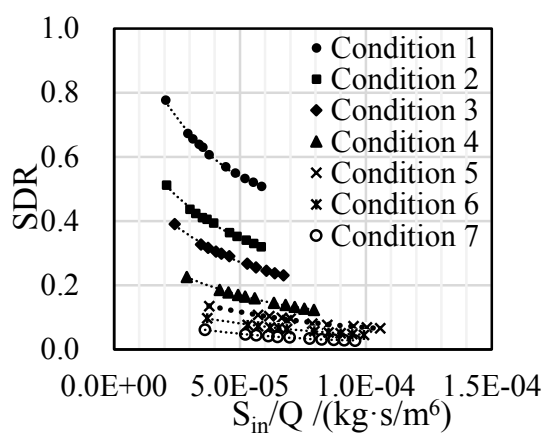

Fig. 7 The relationship between the SDR and inflow sediment coefficient

Fig. 7 shows that the smaller the FRT, the larger and more obvious the influence the inflow sediment coefficient has on the SDR. When the FRT was small, the SDR would change dramatically for a relatively small change in the inflow sediment coefficient. As the FRT increased, the SDR was only slightly affected when the inflow sediment coefficient changed over a relatively wide range. Generally speaking, the inflow sediment concentration and the inflow sediment coefficient affected the SDR more noticeably under small FRT values.

Two inflow sediment gradations were designed according to the real inflow sediment gradation of the TGR. Gradation 1 and Gradation 2 were the inflow sediment gradations before and after the implementation of the upstream cascade reservoirs (Fig. 8).

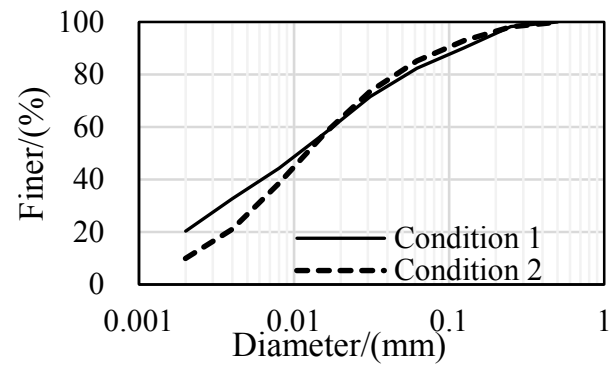

Fig. 8 Inflow sediment gradation

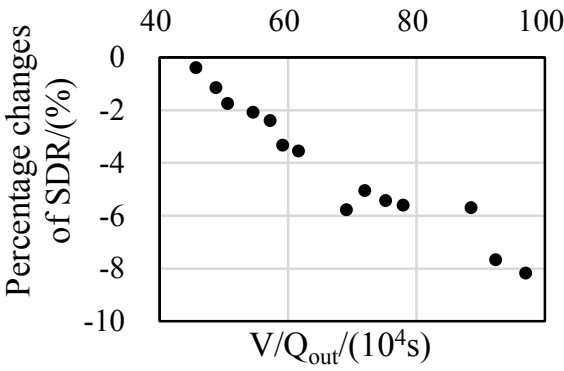

Fig. 9 SDR changes for Gradation 1 and Gradation 2

The most important difference between the two gradations was the content of sediment finer than $0.004 \mathrm{~mm}$ in diameter. The water level at the dam site and the inflow sediment concentration were kept constant, and 14 different inflow rates were selected. The effect that Gradation 2 had on the SDR compared with Gradation 1 for a given combination of dam water levels and inflows is shown in Fig. 9. The SDR for Gradation 2 was always smaller than that of Gradation 1. However, as the FRT increased, the SDR gap between Gradation 2 and Gradation 1 increased.

It would appear that the shape coefficient of the inflow flood represented the different types of flood inflows. The bigger the coefficient, the sharper and thinner the shape of the flood was, and conversely, the smaller the coefficient, the flatter and wider the shape of the flood. Physically, the shape coefficient of the flood, assuming the average discharge of the flood was constant, was much bigger when the hydrodynamic conditions of the flood were much stronger.

Seven combinations of dam water levels and inflow rates were selected in this study (Table 2). For each combination, the inflow flood shape coefficients were investigated by changing the peak flood inflows and by keeping the average inflows constant. The FRTs 
for Conditions 1 to 7 were $34,42,54,69,81,96$, and $120 \times 10^{4} \mathrm{~s}$, respectively. The results (Fig. 10) indicate that the FRT remained the more important factor influencing the SDR when compared with the shape coefficient of the inflow flood. The shape coefficient for the inflow flood had a positive influence on the SDR. The larger the coefficient, the larger the SDR. In addition, these results also showed that the shape coefficient had an obvious influence on the SDR when the FRT was small.

Table. 2 Different combinations of dam water levels and inflow flood rates

\begin{tabular}{cccc}
\hline $\begin{array}{c}\text { Condition } \\
\text { No. }\end{array}$ & $\begin{array}{c}\mathrm{Z} / \\
(\mathrm{m})\end{array}$ & $\begin{array}{c}\mathrm{Q}_{\mathrm{b} \& \mathrm{a}} / \\
\left(\mathrm{m}^{3} / \mathrm{s}\right)\end{array}$ & $\begin{array}{c}\mathrm{Q}_{5} / \\
\left(\mathrm{m}^{3} / \mathrm{s}\right)\end{array}$ \\
\hline 1 & 135 & 30000 & 45600 \\
2 & 140 & 30000 & 40000 \\
3 & 145 & 25000 & 38800 \\
4 & 145 & 20000 & 30000 \\
5 & 150 & 20000 & 30000 \\
6 & 155 & 20000 & 27400 \\
7 & 155 & 15000 & 25000 \\
\hline
\end{tabular}

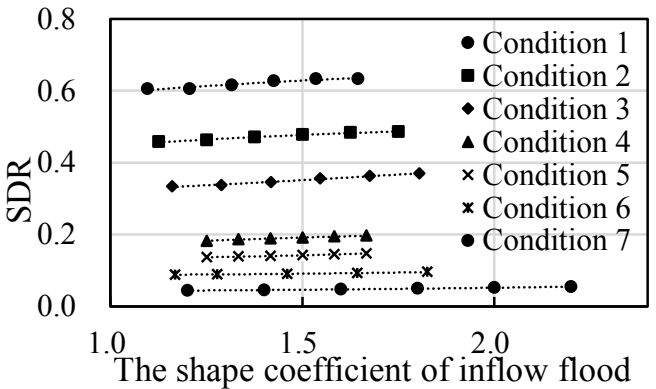

Fig. 10 The relationship between the SDR and the shape coefficient of the inflow flood

\section{Conclusions}

Based on TGR monitoring data, factors influencing the SDR of the TGR were the dam water levels, and the inflow and outflow rates. These factors all had an influence on the SDR, but their correlation with the SDR was relatively low. The water levels at the dam had a negative correlation with the maximum SDR value, while the inflow and outflow rates had a positive correlation. However, the water levels and flow rates did not have an obvious relationship with the minimum values of the SDR. The FRT values, which represented the combined effects of water levels and outflow, strongly correlated with the SDR. The higher the FRT, the lower the SDR. In addition, as the FRT increased, the rate of the SDR decrease slowed.

Additional SDR data were obtained using a mathematical model of reservoir conditions. A sensitivity analysis revealed that the inflow sediment concentration, the inflow sediment gradation, and the shape coefficient of the inflow flood also had influence on the SDR. In addition, the inflow sediment coefficient was introduced to represent the combined influence of the inflow rate and the inflow sediment concentration. The sensitivity of the inflow sediment coefficient was also analysed. The results showed that the FRT was the principal factor influencing the SDR, and that the impact of other factors was limited by the FRT. All the factors had a more obvious influence on the SDR when the FRT was relatively small. When the FRT was large, the SDR was only slightly affected by the other factors. However, the inflow sediment gradation was an exception-it had an increasing influence on the SDR as the FRT increased. The inflow sediment concentration and the inflow sediment coefficient were negatively correlated with the SDR. The higher sediment concentration militated against increased SDRs. In addition, the coarser the inflow sediment gradation, the lower the SDR, and an inflow flood with a sharp, thin shape helped increase the SDR.

Theoretically speaking, the most effective measure for increasing the SDR would be to lower the water level and increase the outflow of the TGR. However, in practice, other concerns have to be addressed in addition to sediment issues, and in recent years, the flood control level of the TGR has been raised. Because of this, the inflow sediment gradation should be taken into consideration along with other factors. Sediment gradation is gradually getting coarser, which will further reduce the SDR when the FRT increases. 


\section{Acknowledgement}

This work was funded by the National Key R\&D Plan (Grant No. 2017YFC0405305), the International S\&T Cooperation Program of China (Grant No. 2015DFR70980), and the Scientific Program of China institute of Water Resources and Hydropower Research (Grant Nos. SE0145B792017 and SE0145B702017).

\section{References}

1. G.M. Brune, Trans. Am. Geophys. Union, 34, 407-418(1953)

2. S.E. Lewis, et al., Water Resources Research, 49, 1017-1029(2013)

3. C. Zhang, et al., Yellow River, 35, 19-23(2013)

4. X. Fu, et al., Sci. China Tech. Sci., 854-862(2010)

5. R.Y. Huang and B.L. Fan. Advances in River Sediment Research, 1303-1308 (Taylor \& Francis Group, Fukuoka, 2013)

6. G. Chen, J. Yuan, and Q. Xu, Advances in Water Science, 23, 335-362(2012)

7. C. Hu, et al., Research and Simulation Technology on Sediment Movement of Three Gorges Project (Science Press, 2017) 